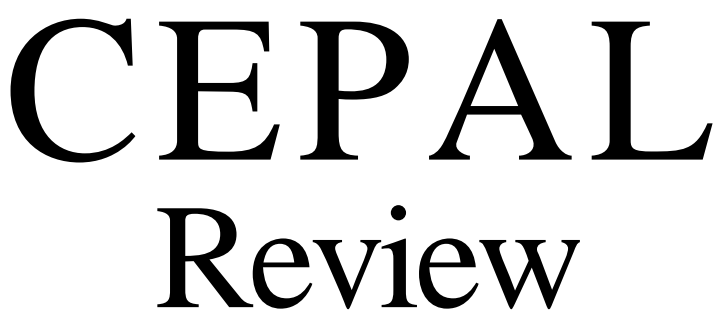

Executive Secretary

Norberto González

Deputy Executive Secretary for

Economic and Social Development

Gert Rosenthal

Deputy Executive Secretary for

Co-operation and Support Services

Robert T. Brown

Technical Secretary

Adolfo Gurrieri

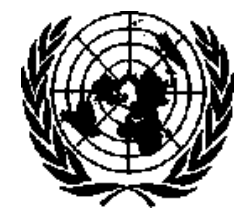

UNITED NATIONS

ECONOMIC COMMISSION FOR LATIN AMERICA AND THE CARIBBEAN

SANTIAGO, CHILE, DECEMBER 1986 


\section{CEP AL}

Review

Santiago, Chile

Number 30

\section{CONTENTS}

Reactivation and development: the great commitment of Latin America and the Caribbean.

Norberto González,

Alleviation of the debt burden: historical experience and present need. Carlos Massad.

From austerity measures to structural adjustment. Lucio Geller and Víctor Tokman.

External debt and the reform of the international monetary system. Arturo O'Connell.

The origin and magnitude of the recessionary adjustment in Latin America.

Richard L Ground.

Turning page in relations between Latin America and the Caribbean countries. Elvio Baldinelli.

The international division of industrial labour and the core-periphery concept.

Kimmo Kiljunen.

Services: a disquieting link between Latin America and the world economy. Francisco Javier Prieto.

Technology transfer in the mining sector: options for the Latin American Mining Organization (OLAMI). Michael Nelson.

The role of the public sector and transnational corporations in the mining development of

Mining development in relation to the origin of capital. Patricio Jones.

New objectives for the development of mining resources. Rolando Sanz Guerrero.

Recent BCLAC publications. 


\title{
Reactivation and development: the great commitment of Latin America and the Caribbean
}

\author{
Norberto González, Executive Secretary of ECLAC \\ I \\ The economic crisis: \\ its evolution and the future outlook
}

From the viewpoint of economic development, the first half of the 1980s has been lost for most of the countries of Latin America and the Caribbean. Unfortunately, if the present economic and social conditions persist, many of them will also have to lose the second half, for the declines registered in the last five years in per capita income are so marked that it will be difficult for the region to recover by 1990 the level which it had already reached in 1980. Consequently, as matters stand it is imperative to promote first of all the recovery and then the sustained growth of the economies. This calls for the application of suitable domestic policies, the existence of a favourable external environment, and active international and regional co-operation.

\section{The origin and consequences of the crisis}

The stagnation and regression which began in 1981 took place after a long period of growth and change in the economies and societies of Latin America. During the period between the end of the Second World War and the end of the last decade, many countries made considerable progress in industrialization, modernized important parts of the agricultural sector, made significant changes in the structure of their external relations, underwent a marked process of urbanization, and witnessed the growth of broad intermediate strata. Of course the nature and pace of these changes have been uneven, not only between the different countries of the region, but also within individual countries, and big differences have persisted as regards productivity within each sector, while underemployment of labour continues unabated and large sectors of the population continue to subsist in conditions of extreme poverty.

Thus, the present crisis has interrupted the progress that was being made and has intensified the existing contrasts, adversely affecting the countries in both economic and social matters and in their capacity to manage their economies in a more autonomous manner.

As regards the economy, the per capita product for the region as a whole was 9\% lower in 1985 than in 1980, while capital formation fell even more sharply, as is shown by the drop in the investment coefficient from $26 \%$ in 1980 to only $16 \%$ in 1985. Furthermore, because of the decline in domestic expenditure, a substantial amount of installed capacity is underutilized in many branches of production.

At the social level, unemployment and underemployment have grown in most of the countries, affecting all categories of the labour force, but especially young people and women. At the same time, real wages have gone down and poverty has become more widespread and acute. Although the crisis has affected the poorest sectors with particular severity, the intermediate strata have also suffered its impact.

The economies have become more vulnerable to external events which are beyond the coptrol of the countries of the region. The leeway for economic policy action has been considerably narrowed by balance-of-payments difficulties and by the pressure of inflationary processes which have become more widespread and acute and have in many countries attained unprecedented levels of intensity. 
At the same time, the capacity of the public sector to take care of the needs of marginal sectors and to engage in social and development expenditure has been seriously limited. These limitations are due to the drop in public revenue caused by the reduction in economic activity and the addition of a new function to the State's many existing responsibilities: that of servicing the external debt. In more than a few cases this involves debt contracted not only by the public sector but also that originally taken out by the private sector.

A situation is thus taking shape which can potentially give rise to growing tensions that can affect social and political stability and, in particular, can have adverse effects on the consolidation of democracy in the region.

Although the crisis has undeniable conjunctural aspects, it is obvious that it also has structural features and that its consequences are likely to be of long duration. Thus, if present trends continue, a significant part of public revenue, national saving and export income will need to be devoted for a number of years to paying the debt service instead of taking care of economic and social development needs. Moreover, the low investment registered thus far in the 1980s will tend to reduce both the growth rate and the modernization of production capacity. This, in turn, would seriously affect the possibility of adapting the structure of production to the rapid technological innovations which are taking place in the developed world and it would limit the future capacity of our economies to compete globally. Those countries which have a more diversified and efficient structure of production and technology will find it easier to export the fastest-growing product lines on international markets.

\section{Alternative economic development projections}

What are the future implications likely to be if there is a continuation of both the current international tendencies and the way in which the domestic adjustment has been carried out so far?

In order to answer this question, it is worth looking at the external financing that would be needed to recover by 1990 the per capita product which the countries of the region registerd back in 1980: a very modest goal, of course, since it would mean that from the point of view of development and well-being a whole decade would have been lost. In this event, all that would be done in the rest of this decade would be to provide the bases for more dynamic growth in the 1990s, so that it would be possible to double the region's product by the end of the century.

With regard to the present decade, it would appear that this objective could be reached in some countries, but would be difficult to attain in others, especially the smallest ones. For the region as a whole, assuming that the real price of oil stabilized at around US\$ 17 per barrel, the achievement of this goal would call for average external financing approximately equal to the net annual external payments of profits and interest made during 1983-1985. In fact, however, during that period the region's net external financing amounted to only one-sixth of that figure. In this respect it is worth emphasizing that the fall in oil prices has considerably increased the amount of external financing required, since the region as a whole is a net oil exporter. Clearly, however, the effect of this drop in oil prices differs as between different countries.

The achievement of such a modest objective would also call for a substantial increase in national saving and investment, both of which would have to increase sharply with respect to the product.

Even if this growth target were reached, the present situation as regards unemployment and poverty would continue deteriorating, for a high proportion of those entering the labour force between now and 1990 would not find productive employment.

This would be reflected in an increase in open unemployment, underemployment and marginal activities, and a deterioration in the living conditions of the population. It is easy to appreciate how dangerous this would be for the social and political stability of our countries.

Such an unfavourable scenario is not necessarily inevitable, however, for the possibilities of overcoming the problems would be much more favourable if, together with an improvement in domestic policies, there were a reduction in protectionism in the developed countries, a decline in interest payments, or an improvement in the terms of trade of the region. 
In order to illustrate the incidence of these latter factors, two hypothetical examples may be considered. The first concerns the real rates of interest paid by the region: if these declined by two percentage points and thus drew close to the level registered on the second half of the 1970s, the net external financing requirements mentioned earlier would be reduced by $25 \%$. The second concerns the terms of trade. If by 1990 commodity prices regained only half of the deterioration suffered in the first half of the present decade, the net external financing needs of the region would be reduced by about one-third. This calculation excludes petroleum, whose uncertain future makes necessary an assumption such as that mentioned earlier.

These figures, although purely illustrative, highlight the importance of international cooperation for tackling and overcoming the challenge of the crisis and the external debt.

I should like to emphasize a conclusion which emerges from the foregoing. The origin and development of the present crisis have been affected by both short and long-term elements of an external and a domestic nature. In effect, the debt and financial problems are inextricably linked with more profound structural aspects. At the international level, fundamental changes are taking place in the structure of demand, in technology and in the productive systems of the developed countries, while modifications have also taken place in the rules governing international trade and finance. Taken together, these changes have accentuated the asymmetrical nature of the external relations of Latin America and the Caribbean. At the same time, at the domestic level, it is necessary to acknowledge the sluggish development of certain sectors, the inability to give productive employment to the labour force, and the persistent inequalities in income distribution and indeed in economic and social opportunities generally.

The projections examined above show that —unless there are favourable changes in international and regional co-operation, in the adjustment process, and in domestic policies - the recession will last for a long time in many countries of the region, thus widening the gap traditionally separating Latin America and the Caribbean from the industrialized economies as well as the more recent gap between the region and certain economies of the Third World which have displayed great dynamism.

\section{II}

\section{Towards reactivation and development}

In the years to come, the countries of Latin America and the Caribbean will face the challenge of combining the immediate objective of economic reactivation with other short, medium and longterm goals. They will have to prepare their economies to compete internationally while simultaneously overcoming domestic structural problems which have stubbornly resisted the solutions applied so far.

At the same time, it will be necessary to apply adjustment and inflation-control policies, which will continue to be vital.

It is important to avoid an excessively sharp distinction between the short and the medium and long terms which causes the objectives of the orderly functioning of the economy (such as the maintenance of macroeconomic balance) to appear to conflict with those of the development and transformation of economies and societies. The fact is that all these objectives must be sought simultaneously, although the need and the possibility for doing this may vary from one country to another and may even vary within a single country over time. Consequently, the relative emphasis placed on each of these objectives must be gradually adapted to the specific features of each case. Indeed, if the countries waited for the end of the crisis before concerning themselves with structural problems related to changes in the world economy and to their own domestic shortcomings and imbalances, they would run the risk of losing even more ground internationally and, at the domestic 
level, suffering an aggravation of their economic and social conditions which would undermine their future development possibilities.

\section{Adjustment, stabilization and reactivation}

For the reasons already noted, the reactivation must not be delayed. If it is to be carried out in a manner compatible with adjustment and stabilization, however, it will be necessary to review the orientation and content of the policies with which these problems have been tackled so far. This means reconsidering the approach that has been taken to the debt problem, as well as the way domestic policies and international and regional co-operation have been operating.

\section{a) Towards a new approach to the debt}

The external debt lies at the very centre of the present crisis. It may be recalled firstly that in Latin America and the Caribbean as a whole the interest payments on the debt currently absorb no less than 36\% of total exports, and secondly that between 1982 and 1985 the region transferred US\$ 106 billion, abroad: a sum equivalent to over a quarter of the total external debt.

The enormous economic cost represented by the debt service can seriously compromise the economic, social and political stability of the countries. Consequently, in dealing with the debt problem it must be borne in mind that it is not just of a financial or economic nature. For this reason, many countries of the region, and especially those comprising the Cartagena Consensus, have stressed the urgent need to restore growth in the Latin American economies and have put forward concrete emergency ideas for avoiding a further deterioration of the present situation. The truth is that if development is subordinated to debt servicing requirements, the consolidation of democracy in the region will be jeopardized.

Tackling the debt problem calls for a dialogue among the four groups of agents involved: the governments of the debtor countries, the international private banks, the international financing agencies, and the governments of the creditor countries.

Moreover, in the dialogue and related international negotiations, the debt must be linked with other financial and trade aspects, since otherwise the asymmetrical nature of the adjustment causes its burden to fall entirely on the debtors, thus increasing its recessive impact.

The adjustment policies applied so far by many countries of the region sought to generate the necessary trade surpluses to pay the debt interest through export growth and import substitution. In seeking this, however, they faced an extremely unfavourable external environment. Because of this and of the short time in which they had to make the adjustment, those trade surpluses were obtained mainly through a very severe contraction in imports. This, in turn, caused a decline in domestic economic activity and led to higher unemployment and the underutilization of productive capacity.

Undoubtedly there have been some positive developments in the debt renegotiations, in the sense that commissions and spreads have been reduced, the amounts renegotiated have been increased, and the repayment periods have been extended. Furthermore, it is true that nominal international interest rates have gone down.

However, these changes, though favourable, have not been sufficient to give grounds for expecting that the Latin American and Caribbean economies will perform satisfactorily in the next few years. Thus, in 1985 the unfavourable impact of the drop in export prices reduced the export income of the region by US\$ 4 billion, while the decline in international interest rates had a favourable impact of only US\$ 1 billion.

Moreover, up to now the justification of the adjustment process advocated by the creditors has been based on the assumption that this process would be of relatively short duration, since the recovery of the international economy would spontaneously engender a more dynamic growth of Latin American exports, and hence a more rapid economic revival of the region. It was therefore presumed that the effort required would also only be of short duration.

These assumptions must be reviewed both in the light of the experience of the last few years and the current situation. Although a recovery of the developed economies may be expected in the near 
future, if it does take place it will probably be only moderate. Moreover, the side effects on the Latin American and Caribbean economies will be quite small: firstly, because a high proportion of the region's exports are made up of primary commodities for which demand is flagging; secondly, because of the obstacles encountered by the exports of the region in gaining access to the markets of the developed countries; and thirdly, because of the difficulties in financing trade. Thus, the growth experienced by the OECD economies in 1985 did not prevent the value of Latin American exports from falling by $6 \%$, or the terms of trade from declining almost $3 \%$ compared with the previous year.

If the spontaneous recovery does not operate effectively, and if it will need an extended period to materialize, the approach to the adjustment process and to international co-operation will have to be changed. Recessive adjustment cannot become a permanent feature of the Latin American economies nor a way of life for the peoples of the region. Indeed, the increase in social tension that has already begun to become evident in several countries as a result of recessive adjustment policies proves that such policies cannot be insisted on for long without jeopardizing both the future development of the nations and their social and political stability.

\section{b) Selective economic adjustment and stabilization policies}

The experience of a number of countries of the region shows how important it is for domestic policies to be based on realistic approaches and flexible conceptual models. Just as in the past there were cases of excessive protectionism and State intervention, so in recent years some countries have applied neo-liberal systems which have had a negative impact on productive capacity and export diversification and have accentuated existing economic and social inequalities. In this respect, it should be recalled that the real proof of the usefulness of economic theories depends on how accurately they interpret the situation of each country and the contribution they make to the formulation of suitable economic policies.

Although obtaining and preserving macroeconomic balances will obviously continue to be very important for both adjustment and handling inflation, it is nevertheless clear that such balances must be made compatible with the goals of reactivation and development. To such ends, there should be an adequate degree of selectivity in economic policy. For example, if there is excessive overall demand, not all expenditure components need be cut back to the same extent. Non-essential or low-priority consumption can be strongly discouraged, while steps are taken to maintain or even increase expenditure geared to generating employment, improving the standard of living of the poorest groups, increasing investment in productive sectors, and ensuring that export promotion and import substitution policies are sustained or expanded.

Policy selectivity can also take the form of special programmes to promote these objectives. Several Latin American and Caribbean countries have recently been executing programmes to generate productive employment which requires fewer imported inputs, to alleviate poverty, to increase export capacity, and to help exports to compete more successfully in international markets.

An appraisal of these experiences could serve to strengthen them and make them more effective. In order to do this, I think it would be very useful to discuss the social impact of the crisis and ways of responding to this challenge, in order to facilitate an exchange of experiences and ideas about the social policies which are being applied or could be applied in this field.

Similarly, consideration should be given to stabilization policies, in order to determine how they could distribute the effort more equitably and to make them compatible with reactivation and growth. Recent experiences in stabilization in some countries of the region, which are somewhat different from the traditional orthodox methods, have brought some degree of creativity to this field.

\section{c) International co-operation}

It is imperative to achieve the kind of international co-operation in both trade and finance that will make it possible to reduce the debt-servicing burden, so as to lessen the corresponding sacrifice 
of consumption and investment. Without this kind of co-operation, however well designed and applied domestic policies may be they will not be nearly enough.

In the area of trade, protectionism must be reduced so that Latin American exports can have easier access to the developed countries' markets. A recovery in the terms of trade and, in particular, of commodity prices depends basically on whether the policies of the developed countries achieve a faster recovery and more dynamic and sustained growth of their economies.

International financial co-operation, for its part, can reduce the need to restrict imports, since such co-operation makes it possible to reduce the transfer of real resources abroad for debt-servicing. Indeed, if real international interest rates declined to a point close to their historical levels, this would greatly reduce the debt-servicing burden.

However, interest payments do not depend solely on the evolution of international interest rates. Both within and outside the region, various ideas have been put forward regarding the terms that could be agreed between creditors and debtors for debt-servicing, in order to reduce the burden in this respect.

Some of these proposed strategies call for debt-servicing payments to be limited in line with certain criteria of the debtor's capacity to make them. Other proposals have been put forward which involve reducing the debt principal or interest rates.

Another important aspect of international financial co-operation is connected with the volume and terms of the international capital flows to Latin America and the Caribbean, which are directly linked with the question of conditionality. There is no denying that the countries of the region need to maintain a level of discipline which will enable them to grow, to come to grips with the problem of the debt, and to keep inflation under control. The ways of ensuring this discipline, however, must take account of the special features and potential of each country and the need to preserve the autonomy of each government in managing its economic policies and determining the direction and pace of its economic and social development.

This explains the concern in the region today over some proposals which would not only signify that short-term conditionality would not be adapted to development needs, but additionally would introduce new criteria for long-term conditionality and would therefore lead to the widespread application of both types of conditionality to all external sources of financing. The application of more stringent conditionality in respect of the use of insufficient resources could cause the problems of access to those scarce resources to deepen the crisis instead of helping to resolve it.

The initiative proposed late in 1985 by the United States Secretary of the Treasury represents a positive step, since it recognizes the need for deliberate action by governments of the creditor countries and the international private banks to place the debt problem squarely in the context of economic growth of the debtor countries. However, the amounts announced are clearly inadequate, since they would make it possible to finance only a quarter of the interest being paid by the debtor countries covered by the initiative. Moreover, the proposal includes the application to all sources of financing of a kind of conditionality which is not yet fully defined. The form of this conditionality can affect both the growth rate of the debtor countries and the autonomy of their governments to determine their development strategies and economic policies.

\section{d) Regional co-operation}

With regard to regional co-operation, it is paradoxical that intra-regional trade has declined as a proportion of total trade just when its growth is most needed. As there is underutilized production capacity in virtually every country of the region, a balanced increase in regional trade would help to reactivate the economies despite the balance-of-payments constraints.

In recent years, the forms of technological, production and trade co-operation among enterprises from different countries of Latin America and the Caribbean have multiplied. The ECAC secretariat is helping to extend and deepen these new forms of co-operation, and to this end it has worked closely with governments, the private sector and public enterprises. 
In the final analysis, regional co-operation depends on the will of the countries of Latin America and the Caribbean, because the region already has the institutions and experience which can serve as valuable instruments for efforts of this kind aimed at strengthening regional co-operation and seeking a dynamic source of growth within the region itself. The crisis makes it more urgent than ever to give a strong impetus to regional co- operation. In the present economic situation, effective measures must be taken to strengthen the links between our economies and to make use of the rich potential that the regional market offers. Integration, as I said before, would not only help to reactivate our economies but would also be an instrument for improving their efficiency, increasing the bargaining power of the region, and securing a better place in the international economy. In this connection, the ALADI round of negotiations provides a practical opportunity to give regional co-operation a shot in the arm and thereby increase trade as a means of contributing to reactivation.

\section{Development strategies}

Domestic medium and long-term development strategies must also be adapted to meet the challenges $l_{i j}$ hich will be faced by the countries of the region in the coming years. For the present, I shall focus attention on a few objectives which are of course not the only ones, but which seem to me the most important.

It is necessary to prepare the economies so that they will be more competitive in international markets and can increase the productive absorption of manpower; changes must also be made in the production structure so that it can respond creatively to the changes in the world economy. At the same time, there should be a more equitable distribution of the fruits of development and of economic opportunities, as well as greater participation of all sectors in economic and social decisions.

In order to achieve these goals, in addition to the international and regional co-operation to which I already referred there must also be a well-organized internal effort.

\section{a) More austere development}

International financial flows will undoubtedly be very limited, and this, added to the debt interest payments, makes it unlikely that the region can expect a major net resource contribution from abroad. Development will therefore depend primarily on domestic efforts, which thus assume decisive importance, although of course adequate international co-operation will still be required to complement them.

One basic requirement will undoubtedly be a substantial increase in savings and investment. It is not only the expansion of productive capacity which depends on this, but also its modernization, which in turn is an essential prerequisite for competing in international markets. If such expansion is to be achieved, the consumption patterns of the middle and upper income levels cannot continue to imitate slavishly those of the developed countries, particularly in the case of items with a high direct or indirect imported content. In the environment of intensive intercommunication which now prevails it would be neither possible nor desirable to cut ourselves off from the evolution of world consumption patterns, but suitable policies can be applied to discourage non-essential consumption and to stimulate and mobilize savings.

The reduction of defence spending, which in some countries attains a high proportion of the national income and the fiscal budget, would free resources for increasing saving and taking care of essential social needs.

The channelling of investment is also a matter of high priority. In this respect, it is very important for many countries of the region to reconstruct and discipline their domestic financial systems so as to make them more efficient and to ensure that they channel the funds in line with economic and social priorities of general interest. Financial intermediation must be functionally suited to the requirements of productive activity, and there must not be any encouragement of 
consumption of low social priority. It is also very important to limit the flight of capital and to secure the return of funds which have already left the country,

\section{b) Better articulation of the production sectors}

Industrial, agricultural and mining strategies should also be reviewed. In developing these sectors, selective advantage should be taken of the opportunities offered by the national, regional and international markets.

Industrialization should play a leading role in the future development of the region. The vulnerability and the limited options currently affecting economies which rely primarily on raw material exports show the importance of diversifying the structure of production and of exports by increasing the production of manufactures. Policies aimed at promoting and orienting industrialization, which have been essential in the past, are even more important at this stage. But they must also be brought up to date in order that they may bring about those changes in the structure of production which are necessary to achieve a dynamic insertion of the Latin American and Caribbean economies into the world economy.

In this regard, it may be recalled that the region's comparative advantages as regards labourintensive and natural-resource-intensive production processes are being eroded by the introduction of new technologies in the developed countries which often reduce the advantage of having low-cost labour. In order to identify those sectors and processes in which the region can still create advantages, the direction and intensity of such technological changes must be assessed accurately, so that production and export efforts may be concentrated on those activities which have the best prospects and so that decisions can be taken on the measures that should be adopted to permit domestic industries to respond adequately to the new situation and to create a more diversified and dynamic export structure.

In today's increasingly interdependent and competitive world, innovative capacity is an essential requisite for competitiveness. In this regard, our region has a long way to go, for in the past, despite certain very commendable efforts, it has been predominantly dependent for its technology on the exterior. Innovation is not something which only concerns those firms interested in exporting. Rather, society as a whole must be aware of the importance of innovation and, to this end, it must give due attention to the qualitative content of education. In order for innovation and efficiency to be promoted, there must also be a more explicit articulation between policies regarding technology and those pertaining to production and suitable institutional arrangements must be developed so that efforts in the area of technology can be concentrated on objectives that will enhance the competitiveness both of exports and of import-substitution industries.

Another fundamental question is that of employment. As already pointed out, various sectors of production have not acted very effectively as far as the productive use of labour is concerned.

As regards industry, greater support should be given to small and medium-sized enterprises and suitable forms of subcontracting should be identified and disseminated in order to strengthen the articulation of these firms with large corporations, since this would enhance their development and create more jobs in competitive activities. Some countries in other regions have done this and it has also become the trend recently in the developed countries, which in many cases now favour production by smaller companies.

With respect to agriculture, I would like to stress two points, namely the approach to be taken as regards technology for the development of that sector, and the problems of peasant agriculture. As regards the first point, the approach until now has often been to promote the use of capital-intensive labour-saving technologies rather than technologies which would make it possible to increase yields per hectare. In modern agriculture, mechanization is an irreversible phenomenon, and it is also necessary in order to increase overall agricultural production. Nevertheless, if greater attention were given to increasing the use of agricultural inputs which do not require much capital (such as biological and chemical inputs) and use were made of more advanced methods of cultivation it would be possible to increase total production, both for domestic consumption and for export. As regards 
the second point, I feel it is very important to pay greater attention to the specific problems of peasant agriculture, where a very high proportion of underemployment, rural marginality and poverty is to be found. In addition, the relationship between the development of manufacturing and that of agriculture and mining must be strengthened. In this connection the increased industrial processing of commodities offers a promising potential for domestic growth and job creation which should be tapped. Moreover, increased processing would also make it possible to diversify exports and to achieve the flexibility required in a world where the demand for unprocessed commodities is sluggish and where protectionist trends prevail in many industrialized economies.

\section{c) The State and the market}

The State and the market are often viewed as having antagonistic roles. In my opinion, however, this is an over-simplified view which can lead to erroneous conclusions and policies.

There can be no doubt that the market has a very important role to play. The vigour of private enterprise and its search for efficiency and for new growth opportunities should be used to the full, and to this end unnecessary obstacles to its operation should be avoided. It is equally clear, however, that the State and public enterprises will have a very important role to play over the next few years. Both the world economy and that of Latin America and the Caribbean are going through a period of transition and it is important to introduce certain structural reforms in our production system. This means that the State, jointly with the private sector, must support the structure of production and guide efforts aimed at increasing efficiency and innovative capacity and facilitating the penetration of new external markets. It is also clear that the State has an important role to play in social development and, in general, in promoting an equitable distribution of the fruits of economic growth. It has a decisive part to play in the search for an adequate balance between social and private values.

\section{d) Social development in the context of participative and democratic societies}

Despite the social changes which have gone hand in hand with economic development, extremely important lags persist which have led the governments of Latin America and the Caribbean at previous ECAC meetings to describe the societies of our region as inequitable. There are, indeed, great differences as regards income, living standards and opportunities. Two clear manifestations of this phenomenon are underemployment and the critical poverty which affects more than one-third of the population. Under such circumstances, continued efforts to achieve greater equity are essential.

As regards the adjustment and stabilization processes, a fairer distribution of efforts and benefits is important not only for ethical reasons but also because it is essential in order to create the consensus required to ensure that such efforts can be maintained over a long period of time. The ability of our governments to lead our countries through these periods of uncertainty and change will depend to a large extent on their ability to maintain this consensus. In this regard, it should be pointed out that the recovery of democracy is compatible with moderate economic growth (such as that which, for the reasons mentioned earlier, the region can be expected to register over the next few years), provided that the political actors representing the social majorities are participants in a sound and prolonged national effort. Development strategies, for their part, must be designed so that the achievement of greater equity is made an indissoluble element of the functioning of the productive and social system.

If these conditions are attained, the consolidation of democratic processes in the region and the progress towards greater economic, social and political participation can make a decisive contribution towards the attainment of a more dynamic and just form of development.

The future of our region depends on our being able to make a considerable internal effort and to concentrate and organize that effort in such a way as to enable us to achieve the great objectives of economic and social development. We must combine imagination and realism if we are to turn the challenges arising from the crisis into opportunities and to lay the foundations for a new stage of 
dynamic and just development. Nevertheless, as I have already pointed out, this internal effort will not be enough unless it is accompanied by adequate international co-operation and unless an impetus is given to regional co-operation.

The year 1988 will mark the fortieth anniversary of the creation of ECLAC. I feel that, rather than seeing this as an occasion for celebration, we must see it as an opportunity for reflection. Our institution has a long-standing tradition of thought linked to action. We are at the service of member governments for examining the problems of the region and assessing which policies can best lead to their solution. In order to carry out this task responsibly and objectively, we need to conduct studies that will enable us to interpret the situation accurately and examine the advantages and limitations of alternative policies. As I have already said, in this work we must keep constantly in touch with governments, with the main actors of society, with the private and labour sectors, and with academic circles whose influence has been growing in all the countries. The secretariat can play a useful role in promoting an exchange of experiences among the countries of the region, as well as critically examining proposals and ideas originating outside it so that we can take up those points which seem useful, without making the mistake of applying them mechanically.

During the past year, we have done a great deal of thinking and have tried to analyse the crisis from a longer-term perspective, seeking to identify both the most effective ways to overcome it and the most suitable strategies for responding to the challenges of the future. The results of our reflections were considered by member governments at the session of the BCAC Committee of the Whole held in Buenos Aires in August 1985.

We shall continue striving to serve all the countries of the region through this work of identifying, analysing and evaluating the problems which hinder our economic and social development. These problems face us today within the framework of an increasingly complex situation, in which the region is highly vulnerable and the selection of strategies and the application of effective policies has become a matter of extreme urgency, in view of the deterioration and the seriousness of the economic and social conditions affecting vast sectors of our populations. We shall persist in our undertaking with determination, and will intensify still further our contacts with the governments of the region as well as with the various economic and social sectors which take part in the development process. 